\title{
Validation of a Persian Short-Form Version of a Standardised Questionnaire Assessing Oral Cancer Knowledge, Practice and Attitudes Among Dentists
}

\author{
Nader Navabi, "Maryam A. Hashemipour, Aida Roughani
}

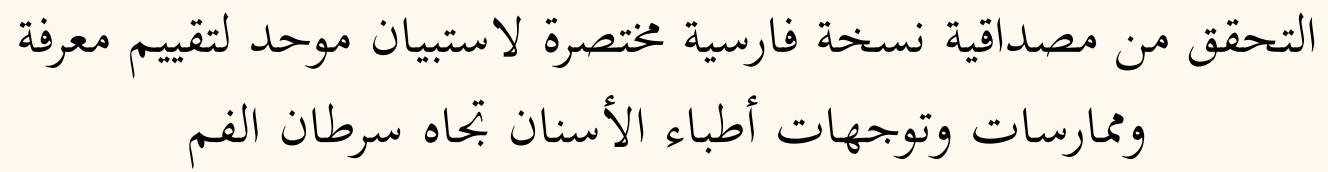

نادر نفابي، مريم السادات هاشميبور، عايده روغانى

ABSTRACT: Objectives: Oral cancer is a global health problem; however, many dentists lack the necessary skills, knowledge and capacity to diagnose oral cancers early. This study aimed to examine the validity and reliability of a Persian short-form version of a standardised questionnaire to assess dentists' knowledge, practice and attitudes towards oral cancer. Methods: This cross-sectional analytical study was carried out in May 2015 in Tehran, Iran. An original 39-item English-language questionnaire developed by Yellowitz et al. was translated into Persian using forward and backward translation methods. A total of 15 dental professionals were asked to assess the questionnaire for content validity. Based on their feedback, a 20-item short-form version was prepared, including six demographic, six knowledge, four attitude and four practice items. The translated short-form questionnaire was subsequently distributed to 973 general dental practitioners attending a dental conference in Tehran. Internal consistency and reliability were assessed with Cronbach's alpha coefficient and item-total correlation calculations. Results: A total of 13 professionals and 313 general dentists participated in the study (response rates: $86.7 \%$ and $32.2 \%$, respectively). After the elimination of six items (two knowledge, two attitude and two practice items), the validity and reliability of the questionnaire was confirmed. Conclusion: The final Persian 14-item version of the questionnaire had acceptable validity and internal consistency. These results indicate that researchers can use this translated short-form version to evaluate oral cancer knowledge, attitudes and practices among Persian-speaking dentists; this will allow for a comparison of data between different populations.

Keywords: Oral Cancer; Knowledge; Attitudes; Dentists; Validity and Reliability; Translations; Questionnaire Design; Iran.

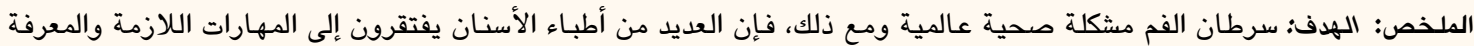

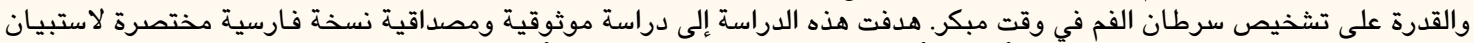

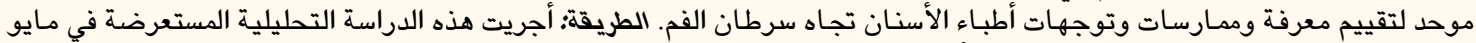

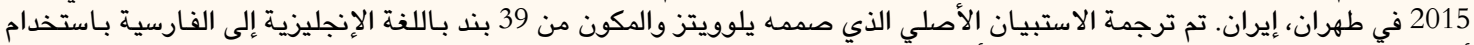

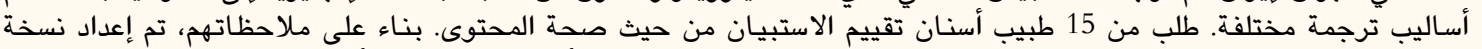

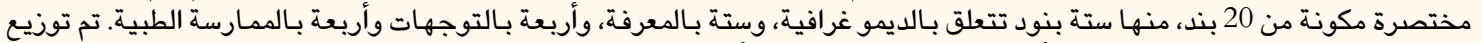

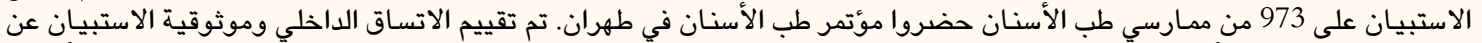

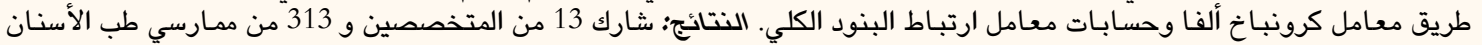

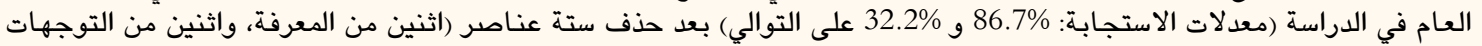

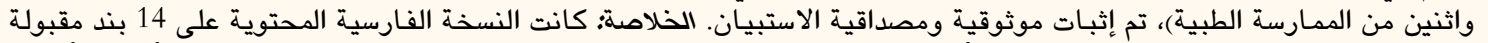

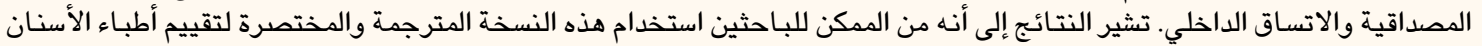

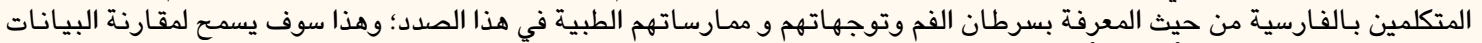
بين مجموعات مختلفة من أطباء الأسنان.

الكلمـات المفتاحية: سرطان الفم؛ المعرفه؛ الاتجاهـات؛ أطباء الأسنان؛ صحة وموثوقية؛ ترجمة؛ تصميم الاستبيان؛ إيران.

\section{AdVANCES IN KNOWLEDGE}

The results of the current study confirmed that the final Persian 14-item version of an existing oral cancer questionnaire had acceptable validity and internal consistency.

This version of the questionnaire can be used in other studies to assess knowledge, attitudes and practices associated with oral cancer among Persian-speaking dentists. 


\section{Application to Patient Care}

Improved knowledge, attitudes and practices among dentists can help prevent oral cancers or ensure an early diagnosis, thus improving patient survival rates.

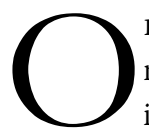

RAL CAVITY CANCERS ARE CONSIDERED A major health risk, especially for individuals in developing countries; approximately 400,000 new cases of oral and pharyngeal cancer are identified annually worldwide. ${ }^{1}$ In addition, almost 13,000 deaths occur globally per year due to squamous carcinomas of the head and neck and there has been a relative increase in the incidence of oral cancer in recent decades. ${ }^{2}$ Unfortunately, many oral cancer lesions are not diagnosed until they have reached advanced stages; for example, squamous cell carcinomas in the oropharynx may be confused with pharyngitis and viral tonsillitis, consequently resulting in delays in diagnosis and treatment. ${ }^{3}$ Since the majority of individuals undergo dental check-ups at least once or twice a year, dentists can carry out thorough and accurate examinations of regions at high risk for oral cancer, potentially allowing for an early diagnosis. ${ }^{4}$ However, many dentists lack the necessary skills, knowledge and capacity to diagnose oral cancers early. ${ }^{4-6}$

Previous studies have emphasised the importance of promoting knowledge of oral cancer among dentists so as to ensure rapid patient screening, successful treatments and decreased mortality rates. 5 Therefore, the design and implementation of a standard validated questionnaire in this field is important; it would reduce bias in relation to the selection of questions, thereby allowing a more accurate comparison of results from different studies. Yellowitz et al. introduced the first comprehensive questionnaire to determine dentists' knowledge, attitudes and practices in relation to oral cancer. However, many dentists did not have the time or inclination to answer all of the questions in the original 39-item questionnaire; the incomplete questionnaires resulted in a decrease in the accuracy of responses, thereby compromising the validity of the evaluation. ${ }^{7}$ The present study was undertaken to validate a Persian short-form version of Yellowitz et al's original English-language questionnaire on dentists' oral cancer knowledge, attitudes and practices.?

\section{Methods}

This cross-sectional analytical study took place in May 2015 in Kerman and Tehran, Iran. An original English-language questionnaire for dentists developed by Yellowitz et al. on oral cancer knowledge, attitudes and practices was translated into Persian. ${ }^{7}$ Five items (questions 22, 25, 31, 37 and 39) in the original questionnaire were deemed to be specific to the USA and were removed at the agreement of the translators and researchers. The resulting 34-item questionnaire was first translated based on standard principles; as such, two experts in translating dental technical terms separately carried out a literal translation of the original English-language questionnaire into Persian. ${ }^{8}$ If the literal translation resulted in distortion of the meaning of a question, a conceptual translation was performed. Subsequently, two other individuals translated the questionnaire back into English; these individuals were experienced in translating from Persian into English and had not previously read the English version of the questionnaire. The resulting translations were then compared with the original text to identify possible discrepancies. Discussions were held among all of the translators until an agreement on the final text was reached. Final corrections were subsequently made to the questionnaire items with discrepancies. ${ }^{9}$

The final Persian translation of the 34-item questionnaire was distributed to 10 oral medicine and five oral/maxillofacial pathology specialists from Kerman Dental School, Kerman. In order to prepare a short-form version of the questionnaire, the specialists were asked to evaluate the questionnaire and identify items that could be removed. As per the feedback obtained, only items deemed necessary by $>80 \%$ of the specialists were included in the shortform version of the questionnaire. ${ }^{9}$ This resulted in the final inclusion of six demographic and 14 oral cancer items (six knowledge, four attitude and four practice items). One of the questions eliminated from the final version was related to precancerous lesions.

Subsequently, a total of 973 general dental practitioners participating in the $55^{\text {th }}$ Annual Congress of the Iranian Dental Association in Tehran were recruited via a convenience sampling method to complete the Persian short-form version of the questionnaire. The necessary sample size was calculated to be 300 ( $\alpha=95 \%$; $d=0.05 ; \mathrm{P}=38 \%) .{ }^{10}$ Completed questionnaires in which over $30 \%$ of the questions were unanswered were not included in the analysis.

Data from the questionnaire responses were analysed using the Statistical Package for the Social Sciences (SPSS), Version 21 (IBM Corp., Chicago, 
Table 1: Demographic characteristics of general dental practitioners in Tehran, Iran $(\mathrm{N}=313)$

\begin{tabular}{|c|c|}
\hline Characteristic & n (\%) \\
\hline \multicolumn{2}{|c|}{ Employment status } \\
\hline Private practice & $158(50.5)$ \\
\hline Clinic & $83(26.5)$ \\
\hline Other & $72(23.0)$ \\
\hline \multicolumn{2}{|c|}{ Year of graduation } \\
\hline$\leq 1979$ & 14. (4.5) \\
\hline 1980-1989 & $21(6.7)$ \\
\hline 1990-1999 & $69(22.0)$ \\
\hline 2000-2009 & $111(35.5)$ \\
\hline 2010-2016 & $98(31.3)$ \\
\hline \multicolumn{2}{|l|}{ Age in years } \\
\hline$<40$ & $187(59.7)$ \\
\hline $40-60$ & $107(34.2)$ \\
\hline$\geq 60$ & $19(6.1)$ \\
\hline \multicolumn{2}{|l|}{ Gender } \\
\hline Male & $186(59.4)$ \\
\hline Female & $127(40.6)$ \\
\hline \multicolumn{2}{|c|}{ Previous participation in oral cancer CME programmes } \\
\hline Last year & $45(14.4)$ \\
\hline $2-5$ years before & $69(22.0)$ \\
\hline$>5$ years before & $34(10.9)$ \\
\hline Never & $104(33.2)$ \\
\hline New graduate & $24 .(7.7)$ \\
\hline Not sure & $37(11.8)$ \\
\hline \multicolumn{2}{|c|}{$\begin{array}{l}\text { Interest in participating in future oral cancer CME } \\
\text { programmes }\end{array}$} \\
\hline Yes & 257 (82.1) \\
\hline No & $22(7.0)$ \\
\hline Not sure & $34(10.9)$ \\
\hline
\end{tabular}

CME = continuing medical education

Illinois, USA). Results were analysed descriptively using a Student's t-test and Chi-squared test. The internal consistency and reliability of the questionnaire items were determined using Cronbach's alpha coefficients and item-total correlations. ${ }^{8,9}$ Acceptable cut-off values for Cronbach's alpha coefficients and item-total correlations were set at $\geq 0.70$ and $\geq 0.30$, respectively. If an item resulted in an unacceptable coefficient value, the item was eliminated and the coefficient was recalculated; if the new coefficient was subsequently acceptable, the item was removed
Table 2: Internal consistency and reliability of oral cancer knowledge items in a Persian short-form version of a standardised questionnaire* completed by general dental practitioners in Tehran, Iran $(\mathrm{N}=313)$

\begin{tabular}{|c|c|c|}
\hline Item & $\begin{array}{c}\text { Frequency, }^{\dagger} \\
\%\end{array}$ & $\begin{array}{l}\text { Cronbach's } \\
\text { alpha } \\
\text { coefficient }{ }^{*}\end{array}$ \\
\hline $\begin{array}{l}\text { 1. The most common site } \\
\text { of oral cancer besides the } \\
\text { lips is the tongue and oral } \\
\text { cavity floor }\end{array}$ & 26.7 & 0.32 \\
\hline $\begin{array}{l}\text { 2. The most common } \\
\text { form of oral cancer is } \\
\text { squamous cell carcinoma }\end{array}$ & 66.7 & 0.22 \\
\hline $\begin{array}{l}\text { 3. Oral cancer typically } \\
\text { presents at } 30-49 \text { years } \\
\text { of age }\end{array}$ & 33.3 & 0.33 \\
\hline
\end{tabular}

metastatic lymph nodes

are fixed and non-

tender, with a stony-hard

consistency

5. A two-finger method

is the right method for a

tongue examination for

oral cancer

6. Tobacco and alcohol

consumption are the

most common risk

factors for oral cancer

$I-T$ corr $=$ item-total correlation

"An English-language questionnaire on dentists' oral cancer knowledge attitudes and practices developed by Yellowitz et al..$^{\dagger}$ Using correct responses only. ${ }^{\ddagger}$ This value represents the Cronbach's alpha coefficient after elimination of the item from the questionnaire.

entirely from the final version of the questionnaire. For attitude items, items were scored on a five-point Likert scale, with scores of 1 indicating strongly disagree and 5 indicating strongly agree.

The protocol for this study was approved by the Ethics Committee of the Kerman University of Medical Sciences, Kerman, Iran (\#K.95.62). Informed oral consent was obtained from all of the dentists before participating in this study. All personal and identifying information was kept confidential.

\section{Results}

The Persian short-form version of the questionnaire was completed by 323 general dentists; however, a total of 10 questionnaires were excluded from the study due to unclear responses and a lack of demographic data, resulting in a final sample size of 313 participants (response rate: 32.2\%). Table 1 presents the demographic characteristics of the participants. No significant differences were found between demographic characteristics and oral cancer knowledge, attitudes or practices. With regards to the six knowledge items, the second item had the highest 
Table 3: Reliability of oral cancer attitude items in a Persian short-form version of a standardised questionnaire* completed by general dental practitioners in Tehran, Iran $(\mathrm{N}=313)$

\begin{tabular}{|c|c|c|}
\hline Item & $\begin{array}{c}\text { Frequency, } \\
\%\end{array}$ & $\begin{array}{l}\mathrm{I}-\mathrm{T} \\
\text { corr. }\end{array}$ \\
\hline $\begin{array}{l}\text { 1. I received adequate oral cancer } \\
\text { education at my previous dental } \\
\text { school }\end{array}$ & 41.3 & 0.01 \\
\hline $\begin{array}{l}\text { 2. The quality of my previous } \\
\text { education about oral cancer } \\
\text { examinations is adequate }\end{array}$ & 54.3 & 0.11 \\
\hline 3. & & \\
\hline $\begin{array}{l}\text { a) My knowledge of oral cancer is } \\
\text { up-to-date }\end{array}$ & 26.7 & 0.34 \\
\hline $\begin{array}{l}\text { b) It is necessary to perform annual } \\
\text { oral cancer screening examinations } \\
\text { for patients }>40 \text { years old }\end{array}$ & 82.2 & 0.32 \\
\hline $\begin{array}{l}\text { c) It is easy to refer patients with } \\
\text { suspicious lesions to oral cancer } \\
\text { specialists }\end{array}$ & 92.7 & 0.31 \\
\hline $\begin{array}{l}\text { d) The early detection of oral cancer } \\
\text { increases five-year survival rates }\end{array}$ & 87.9 & 0.31 \\
\hline 4. & & \\
\hline $\begin{array}{l}\text { a) I am well-trained in providing } \\
\text { education on smoking cessation }\end{array}$ & 27.9 & 0.32 \\
\hline $\begin{array}{l}\text { b) I am well-trained in performing } \\
\text { oral cancer examinations }\end{array}$ & 29.2 & 0.32 \\
\hline $\begin{array}{l}\text { c) The majority of dentists can } \\
\text { competently perform oral cancer } \\
\text { examinations }\end{array}$ & 20.2 & 0.33 \\
\hline $\begin{array}{l}\text { d) The majority of physicians can } \\
\text { competently perform oral cancer } \\
\text { examinations }\end{array}$ & 13.4 & 0.32 \\
\hline
\end{tabular}

rate of correct responses (66.7\%). The elimination of any of these six items did not result in acceptable Cronbach's alpha values; however, items five and six were eliminated due to their low item-total correlation coefficients (0.05 and 0.12, respectively) [Table 2]. For the four attitude items, calculation of the item-total correlation coefficients resulted in the elimination of items one and two [Table 3]. In addition, the initial overall Cronbach's alpha value for all of the attitude items was 0.32; this increased to 0.62 (close to the cut-off value of 0.70 ) after elimination of these two items, indicating the necessity of their removal from the final version of the questionnaire.

In the practice section, elimination of none of the individual items resulted in acceptable Cronbach's alpha coefficients [Table 4]. The overall Cronbach's alpha coefficient for all of the practice items was 0.11 ; however, following the removal of items one and two, this was recalculated to be 0.64 (close to the cut-off value of 0.70 ). In addition, these two items exhibited unacceptable item-total correlation coefficients $(0.21$ and 0.04 , respectively). Therefore, these two practice
Table 4: Internal consistency and reliability of ora cancer practice items in a Persian short-form version of a standardised questionnaire* completed by general dental practitioners in Tehran, Iran $(\mathrm{N}=313)$

Frequency,

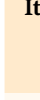

1. Number of biopsies

I-T

of suspicious lesions

performed in the last year

a) 0

b) $<10$

alpha corr

c) $\geq 10$

0.40

0.04

2. Number of patients

with suspicious lesions

werred to specialists in

the last year

a) 0

b) $<10$

65.2

c) $\geq 10$

11.6

3. Referral department for patients with suspicious lesions:

a) Oral medicine $\quad 94.2$

b) Other 5.8

4. Factors evaluated during history-taking:

$\begin{array}{llll}\text { a) Smoking } & 87.2 & 0.13 & 0.54\end{array}$

b) Alcohol consumption $\quad 76.5 \quad 0.11 \quad 0.46$

$\begin{array}{llll}\text { c) Smoking type and } & 76.5 & 0.12 & 0.52\end{array}$

frequency

d) History of other

cancers

e) Family history of

75.2

0.13

0.53

cancer

$0.14 \quad 0.55$

I-T corr $=$ item-total correlation

"An English-language questionnaire on dentists' oral cancer knowledge, attitudes and practices developed by Yellowitz et al. ${ }^{7^{+}}$This value represents the Cronbach's alpha coefficient after elimination of the item from the questionnaire.

items were subsequently eliminated from the final version of the questionnaire. An English version of the final short-form questionnaire is shown in Table 5 .

\section{Discussion}

The current study sought to validate a Persian short-form version of an existing English-language questionnaire assessing dentists' knowledge, practice and attitudes towards oral cancer. ${ }^{7}$ The original questionnaire was translated from English into Persian and then back into English; however, this process can introduce errors. It is vital that the original intention of the author of a questionnaire item not be changed during translation, as the purpose of the translation process is not to rephrase or improve an existing instrument. ${ }^{11}$ Fortunately, the majority of the suggestions made by the specialist evaluators in the current study referred to the style of the translation 
Table 5: Questionnaire items included in the final Persian short-form 14-item version of a standardised questionnaire* assessing oral cancer knowledge, practice and attitudes among dentists

\section{Questionnaire items}

Knowledge

1. The most common site of oral cancer besides the lips is the tongue and oral cavity floor

2. The most common form of oral cancer is squamous cell carcinoma

3. Oral cancer typically presents at 30-49 years of age 4. In oral cancer, metastatic lymph nodes are fixed and nontender, with a stony-hard consistency

\section{Attitude}

5.

a) My knowledge of oral cancer is up-to-date

b) It is necessary to perform annual oral cancer screening examinations for patients $>40$ years old

c) It is easy to refer patients with suspicious lesions to oral cancer specialists

d) The early detection of oral cancer increases five-year survival rates

6.

a) I am well-trained in providing education on smoking cessation

b) I am well-trained in performing oral cancer examinations

c) The majority of dentists can competently perform oral cancer examinations

d) The majority of physicians can competently perform oral cancer examinations

\section{Practice}

7. Referral department for patients with suspicious lesions:

a) Oral medicine

b) Other

8. Factors evaluated during history-taking:

a) Smoking

b) Alcohol consumption

c) Smoking type and frequency

d) History of other cancers

e) Family history of cancer

*An English-language questionnaire on dentists' oral cancer knowledge, attitudes and practices developed by Yellowitz et al. ${ }^{7+}$ Not including six demographic items included in the final questionnaire.

and no translation errors were reported. Overall, the Persian short-form version of the questionnaire exhibited suitable validity and reliability; this is consistent with the findings of other studies. ${ }^{9,12}$ The availability of high-quality translations is of vital importance in order to guarantee the successful implementation of existing questionnaires in other non-English-speaking populations and to assure the international comparability of the results.

A key issue with existing oral cancer questionnaires is variations in the total number of questions, which can range from approximately $12-50 .{ }^{13-15}$ Consequently, this results in divergent scores, making it impossible to compare total scores between studies; for example, Razavi et al. reported an acceptable knowledge score to be $\geq 53.8 \%$ (seven or more correct responses out of 13 questions) among Iranian dentists, while Honarmand et al. reported poor knowledge scores to be $\leq 33.3 \%$ (less than four correct responses out of 12 questions) among senior dental students in Iran. ${ }^{13,15}$ Kujan et al. reported that $81 \%$ of Saudi undergraduate dental students correctly answered all knowledge questions, although the researchers did not define what constituted acceptable knowledge scores. ${ }^{14}$

In the current study, $26.7 \%$ of the dentists correctly answered the knowledge item related to the most common location of oral cancers; this is low in comparison to previous results from the USA and Iran (39\% and $80.9 \%$, respectively). ${ }^{16,17}$ Furthermore, in the study conducted in Iran, Borhan-Mojabi et al. found that only $25.7 \%$ of general medical and dental practitioners were aware that the oral cavity floor is a high-risk area for oral cancer. ${ }^{17}$ In contrast, Dumitrescu et al. reported that 54.3\% of Romanian dental students were aware of this fact. ${ }^{18}$ Overall, $66.7 \%$ of respondents in the present study correctly identified the most common form of oral cancer; this is lower than the percentage of correct responses reported by Alaizari et al. (82.8\%) and higher than those reported by Colella et al. (50.5\%) and RochaBuelvas et al. (52.69\%). ${ }^{19-21}$ Various factors may affect differences in knowledge among dentists, such as potential differences in undergraduate dental curricula worldwide. A total of $33.3 \%$ of the dentists in the current study were aware of the predominant age range in which oral cancer presents. In comparison, Vijay Kumar et al. reported that 59\% of Indian dentists correctly responded to this question. ${ }^{22}$ LópezJornet et al. reported that short-term oral cancer knowledge scores among the general population increased following an educational intervention. ${ }^{23}$

With regards to knowledge of the metastatic lymph node characteristics of oral cancer, $48.6 \%$ of respondents in the current study provided correct responses. Decuseara et al. reported that 54\% of Irish dentists in their study had been adequately trained to palpate lymph nodes to detect oral cancer. ${ }^{24}$ It is often difficult to determine which aspects of oral cancer are most important and should be prioritised in questionnaires assessing oral cancer knowledge. Common symptoms of oral cancer and awareness of diagnostic tools, such as cytology smears, are rarely emphasised..$^{14,16,20}$ A major difference between the final short-form version of the questionnaire used in the present study and those of similar studies was the lack of inclusion of questions assessing awareness of the main risk factors for oral cancer (i.e. smoking and alcohol use). ${ }^{19,22,25,26}$ One reason for removing this 
item from the final version of the short-form questionnaire was because it was deemed relatively easy in comparison to other knowledge-related questions. However, Horowitz et al. reported low overall knowledge of risk factors and signs or symptoms of oral cancer among adults in the general population. ${ }^{27}$ The inclusion of such questions should be re-evaluated in future studies.

With regards to attitudes towards oral cancer, $29.2 \%$ of Iranian respondents in the current study believed that they were well-trained in the performance of oral cancer examinations; this finding is much lower than that reported by Colella et al. $(64.8 \%) .{ }^{20}$ Carter et al. found that significantly more general dental practitioners than general medical practitioners routinely inspected the oral mucosa during patient examinations (95.49\% versus $20.17 \%$; $P<0.001) .{ }^{28}$ In the present study, $82.1 \%$ of the Iranian dentists expressed an interest in attending continuing education programmes regarding oral cancer; this is higher than that reported by Shaila et al. (72\%) and Gajendra et al. (75\%). ${ }^{29,30}$ Dentists have also indicated a need for more training to detect oral cancer, for example in studies by Ariyawardana et al. (70\%), Jaber et al. (37.6\%) and Alaizari et al. (86\%). 19,31,32 Overall, few participants in the current study believed that their oral cancer knowledge was up-todate (26.7\%). In a study by Decuseara et al., 53\% of respondents provided positive responses to a similar question. ${ }^{24}$ Carter et al. also reported that significantly fewer general medical practitioners felt that they had sufficient knowledge regarding the prevention and detection of oral cancers in comparison to general dental practitioners (25.2\% versus 54.1\%; $P<0.001)$; however, both general medical and dental practitioners requested further oral cancer training (71.4\% and $80.4 \%$, respectively). ${ }^{28}$ The majority of the dentists in the current study believed that annual oral cancer examinations were necessary for patients over 40 years old (82.2\%).

Responses to questionnaire items in the practice section indicated that $94.2 \%$ of respondents in the present study referred patients with suspicious oral lesions to specialists; this was consistent with the findings of Vijay Kumar et al. and Dumitrescu et al. (98\% and $92.9 \%$, respectively). ${ }^{18,22}$ In addition, the majority of Iranian dentists in the current study questioned patients about their history of other cancers (75.9\%), family history of cancer (75.2\%) and smoking habits (87.2\%). In a study by RochaBuelvas et al., $22.8 \%$ of South Colombian dentists asked their patients about a family history of cancer while Tanriover et al. found that $70.1 \%$ of Turkish primary care physicians asked patients about their tobacco use habits. ${ }^{21,33}$ Only $27.9 \%$ of Iranian dentists in the present study believed that they possessed the necessary training to instruct their patients on how to quit smoking; in contrast, Kujan et al. observed this rate to be $63 \%$ among Saudi dental undergraduates. ${ }^{14}$ Several studies have posed this question in different formats. ${ }^{22,24,29,34}$ It should be noted that $57 \%$ of the undergraduate dental students in Kujan et al's study believed that it was not their responsibility to encourage patients to give up smoking. ${ }^{14}$ In the final short-form version of the questionnaire designed in the present study, the questionnaire item on the number of biopsies taken was removed; moreover, no items on the number of oral cancer examinations performed were included. Previously, Shaila et al. reported that $29.5 \%$ of Indian dentists took biopsy samples of questionable lesions. ${ }^{29}$ Several previous studies have assessed the number of oral cancer examinations performed among dentists. ${ }^{16,22,24,35}$ Future research should seek to determine the necessity of including such questions in this type of questionnaire.

Determining the awareness, attitudes and practices related to oral cancer among dentists is critical; however, homogeneous study tools are necessary to ensure that the evidence and conclusions drawn from specific research is more widely applicable and comparable between population groups. In addition, short-form questionnaires may result in larger sample sizes, as participants are more likely to complete the entire questionnaire. However, the current study was subject to certain limitations. It is likely that those who did not answer all of the questions had poorer knowledge in comparison to those who did. As such, the knowledge levels of the dentists reported in the current study may have been inaccurate, hence weakening the validity of the results. Further studies are recommended to improve the potential weaknesses of this study.

\section{Conclusion}

The findings from this study indicate that the final Persian 14-item version of a standard questionnaire had acceptable validity and internal consistency. Researchers can use this short-form questionnaire to evaluate Persian-speaking dentists' knowledge of, attitudes towards and practices associated with oral cancer. This would subsequently allow for greater comparison of findings between different populations.

\section{CONFLICT OF INTEREST}

The authors declare no conflicts of interest. 


\section{FUNDING}

This study was supported by the Kerman Dental \& Oral Diseases Research Center and a grant from the Vice Chancellor for Research of the Kerman University of Medical Sciences (grant \#K.95.62).

\section{References}

1. International Agency for Research on Cancer, World Health Organization. World Cancer Report 2008. From: www.iarc.fr/ en/publications/pdfs-online/wcr/2008/ Accessed: Oct 2016.

2. Shah JP, Lydiatt W. Treatment of cancer of the head and neck. CA Cancer J Clin 1995; 45:352-68. doi: 10.3322/canjc lin.45.6.352.

3. Jafari A, Najafi SH, Moradi F, Kharazifard M, Khami M. Delay in the diagnosis and treatment of oral cancer. J Dent (Shiraz) 2013; 14:146-50.

4. Monteiro LS, Warnakulasuriya $S$, Cadilhe $S$, Sousa $D$ Trancoso PF, Antunes L, et al. Oral cancer awareness and knowledge among residents in the Oporto city, Portugal. J Investig Clin Dent 2016; 7:294-303. doi: 10.1111/jicd.12158.

5. Maybury C, Horowitz AM, Yan AF, Green KM, Wang MQ. Maryland dentists' knowledge of oral cancer prevention and early detection. J Calif Dent Assoc 2012; 40:341-50.

6. Alami AY, El Sabbagh RF, Hamdan A. Knowledge of oral cancer among recently graduated medical and dental professionals in Amman, Jordan. J Dent Educ 2013; 77:1356-64.

7. Yellowitz JA, Goodman HS. Assessing physicians' and dentists' oral cancer knowledge, opinions and practices. J Am Dent Assoc 1995; 126:53-60. doi: 10.14219/jada.archive.1995.0024.

8. Navabi N, Nakhaee N, Mirzadeh A. Validation of a Persian version of the Oral Health Impact Profile (OHIP-14). Iran J Public Health 2010; 39:135-9.

9. Slade GD. Derivation and validation of a short-form oral health impact profile. Community Dent Oral Epidemiol 1997; 25:284-90. doi: 10.1111/j.1600-0528.1997.tb00941.x.

10. Kadam P, Bhalerao S. Sample size calculation. Int J Ayurveda Res 2010; 1:55-7. doi: 10.4103/0974-7788.59946.

11. Koller M, Aaronson NK, Blazeby J, Bottomley A, Dewolf L, Fayers P, et al. Translation procedures for standardised quality of life questionnaires: The European Organisation for Research and Treatment of Cancer (EORTC) approach. Eur J Cancer 2007; 43:1810-20. doi: 10.1016/j.ejca.2007.05.029.

12. Yellowitz JA, Horowitz AM, Drury TF, Goodman HS. Survey of U.S. dentists' knowledge and opinions about oral pharyngeal cancer. J Am Dent Assoc 2000; 131:653-61. doi: 10.14 219/jada.archive.2000.0239

13. Razavi SM, Zolfaghari B, Foroohandeh M, Doost ME, Tahani B. Dentists' knowledge, attitude, and practice regarding oral cancer in Iran. J Cancer Educ 2013; 28:335-41. doi: 10.1007/ s13187-013-0460-6.

14. Kujan O, Alzoghaibi I, Azzeghaiby S, Altamimi MA, Tarakji B, Hanouneh S, et al. Knowledge and attitudes of Saudi dental undergraduates on oral cancer. J Cancer Educ 2014; 29:735-8. doi: 10.1007/s13187-014-0647-5.

15. Honarmand M, Hajihosseini A, Akbari F. Oral cancer knowledge of senior dental students in Zahedan, South-East of Iran. Asian Pac J Cancer Prev 2014; 15:3017-20. doi: 10.7314/ APJCP.2014.15.7.3017.
16. Applebaum E, Ruhlen TN, Kronenberg FR, Hayes C, Peters ES. Oral cancer knowledge, attitudes and practices: A survey of dentists and primary care physicians in Massachusetts. J Am Dent Assoc 2009; 140:461-7. doi: 10.14219/jada.arch ive.2009.0196.

17. Borhan-Mojabi K, Moradi A, Yazdabadi A. Evaluating the degree of knowledge on oral cancer among general practitioners and dentists in Qazvin. J Eval Clin Pract 2012; 18:498-501. doi: 10.1111/j.1365-2753.2010.01613.x

18. Dumitrescu AL, Ibric S, Ibric-Cioranu V. Assessing oral cancer knowledge in Romanian undergraduate dental students. J Cancer Educ 2014; 29:506-13. doi: 10.1007/s13187-014-0659-1.

19. Alaizari NA, Al-Maweri SA. Oral cancer: Knowledge, practices and opinions of dentists in Yemen. Asian Pac J Cancer Prev 2014; 15:5627-31. doi: 10.7314/APJCP.2014.15.14.5627.

20. Colella G, Gaeta GM, Moscariello A, Angelillo IF. Oral cancer and dentists: Knowledge, attitudes, and practices in Italy. Oral Oncol 2008; 44:393-9. doi: 10.1016/j.oraloncology.2007.05.005.

21. Rocha-Buelvas A, Hidalgo-Patiño C, Collela G, Angelillo I. Oral cancer and dentists: Knowledge, attitudes and practices in a South Colombian context. Acta Odontol Latinoam 2012; 25:155-62.

22. Vijay Kumar KV, Suresan V. Knowledge, attitude and screening practices of general dentists concerning oral cancer in Bangalore city. Indian J Cancer 2012; 49:33-8. doi: 10.4103/0019-509X. 98915.

23. López-Jornet P, Camacho-Alonso F, Miñano FM, SanchezSiles M. Evaluation of the different strategies to oral cancer knowledge: A randomized controlled study. Psychooncology 2013; 22:1618-23. doi: 10.1002/pon.3189.

24. Decuseara G, MacCarthy D, Menezes G. Oral cancer: Knowledge, practices and opinions of dentists in Ireland. J Ir Dent Assoc 2011; 57:209-14.

25. Al-Maweri SA, Addas A, Tarakji B, Abbas A, Al-Shamiri HM, Alaizari NA, et al. Public awareness and knowledge of oral cancer in Yemen. Asian Pac J Cancer Prev 2014; 15:10861-5. doi: 10.7314/APJCP.2014.15.24.10861.

26. Rahman B, Hawas N, Rahman MM, Rabah AF, Al Kawas S. Assessing dental students' knowledge of oral cancer in the United Arab Emirates. Int Dent J 2013; 63:80-4. doi: 10.1111/ idj.12017.

27. Horowitz AM, Moon HS, Goodman HS, Yellowitz JA. Maryland adults' knowledge of oral cancer and having oral cancer examinations. J Public Health Dent 1998; 58:281-7. doi: 10.1111/j.1752-7325.1998.tb03010.x.

28. Carter LM, Ogden GR. Oral cancer awareness of general medical and general dental practitioners. Br Dent J 2007; 203:E10. doi: 10.1038/bdj.2007.630.

29. Shaila M, Shetty P, Decruz AM, Pai P. The self-reported knowledge, attitude and the practices regarding the early detection of oral cancer and precancerous lesions among the practising dentists of Dakshina Kannada: A pilot study. J Clin Diagn Res 2013; 7:1491-4. doi: 10.7860/JCDR/2013/5321.3171.

30. Gajendra S, Cruz GD, Kumar JV. Oral cancer prevention and early detection: Knowledge, practices, and opinions of oral health care providers in New York state. J Cancer Educ 2006; 21:157-62.

31. Ariyawardana A, Ekanayake L. Screening for oral cancer/precancer: Knowledge and opinions of dentists employed in the public sector dental services of Sri Lanka. Asian Pac J Cancer Prev 2008; 9:615-18 
32. Jaber L, Shaban S, Hariri D. Oral cancer prevention and early detection: Knowledge and practice among Saudi Arabian healthcare practitioners. Int J Health Care Qual Assur 2012; 25:64-74. doi: 10.1108/09526861211192412.

33. Tanriover O, Hidiroglu S, Save D, Akan H, Ay P, Karavus M, et al. Knowledge of oral cancer, preventive attitudes, and behaviors of primary care physicians in Turkey. Eur J Cancer Prev 2014; 23:464-8. doi: 10.1097/CEJ.0000000000000020.
34. Awan KH, Khang TW, Yee TK, Zain RB. Assessing oral cancer knowledge and awareness among Malaysian dental and medical students. J Cancer Res Ther 2014; 10:903-7. doi: 10.4103/09731482.138011.

35. Lehew CW, Kaste LM. Oral cancer prevention and early detection knowledge and practices of Illinois dentists: A brief communication. J Public Health Dent 2007; 67:89-93. doi: 10.1111/j.1752-7325.2007.00020.x.

\section{CPD CREDITS FOR REVIEWERS}

Reviewers of articles submitted to SQUMJ may apply for category 1 continuing professional development (CPD) credits. The Oman Medical Specialty Board will award 1 credit per review. 